\title{
BIOPOLÍTICA, EDUCAÇÃO E EUGENIA NO BRASIL (1911-1945)*
}

\author{
Mozart Linhares da SILVA ${ }^{1}$
}

RESUMO: O artigo tem por objetivo analisar as relações entre educação e biopolítica no Brasil entre os anos de 1911 e 1945, datas consideradas em suas singularidades em função de dois episódios marcantes: a conferência proferida por Batista de Lacerda sobre a positivação da mestiçagem no Congresso Universal das Raças, em Londres, e o fim do Estado Novo. Para problematizar as relações entre eugenia e educação no Brasil lançamos mão de algumas ferramentas foucaltianas, como é o caso de conceitos como biopolítica, governamento, governamentalidade, regimes de verdade e poder-saber. As relações entre eugenia, educação e a política de Estado são consideradas como exemplos de governamentalidade biopolítica, quando o homem brasileiro, o "povo", passou a ser pensado na sua condição de corpo-espécie da população. As questões relacionadas à raça da população assumiram papel importante no discurso político educacional, pois dentre os aspectos mais importantes do movimento eugênico no Brasil, estava a formação de uma consciência eugênica, que deveria ser "incutida" desde a infância. Um movimento intelectual de significativa importância assumiu o discurso eugênico como estratégia biopolítica de melhoria da "raça", e, fora nos anos 1930 que esse movimento alcançou êxito institucional.

PALAVRAS-CHAVE: Educação. Biopolítica. Eugenia. História do Brasil.

\section{Educação e biopolítica: problematização}

Após um século, provavelmente, a população do Brasil será representada, na maior parte, pelos indivíduos de raça branca, latina, e, ao mesmo tempo, o negro e o índio terão sem dúvida desaparecido desta parte da América. (LACERDA, 1911, p.242)

Antes de entrarmos propriamente na análise das relações entre eugenia e educação no Brasil, cumpre fazer algumas considerações conceituais atinentes à ideia de biopolítica e educação. Sustentamos conceitualmente as análises a partir da utilização de algumas das chamadas ferramentas foucaultianas, o que significa que não estamos pretendendo seguir um modelo ou sistema teórico-metodológico rígido, o que seria um contrassenso com a própria concepção que Foucault tinha sobre seus trabalhos, mas, somente, “usar” algumas “categorias” para pensar nossa temática. Veiga-Neto situa esta problemática dos usos e abusos de Foucault ressaltando a positividade de certa “infidelidade" com o pensamento do autor ao colocarmos no âmbito de suas redes

\footnotetext{
* Esta pesquisa conta com apoio do CNPq (Edital Ciências Humanas), FAPERGS e PUIC/UNISC.

${ }^{1}$ UNISC - Universidade de Santa Cruz do Sul. Departamento de História e Geografia. Santa Cruz do Sul - RS - Brasil.96815-900 - mozartt@terra.com.br.
} 
discursivas o que ele jamais disse ou mesmo diria. Lançar mão das ferramentas do autor, adentrar sua oficina e usar suas ferramentas, nos coloca o dilema "de sermos ou não (sermos) mais (ou menos) fiéis ao filósofo” (VEIGA-NETO, 2006, p. 82). A resposta a esse dilema é justamente a afirmação dessa “infidelidade”, entendida como fidelidade a um pensamento que não deseja seguidores ou discípulos cativos. Usar Foucault aqui, segundo Veiga-Neto,

[...] pode significar tomar simplesmente aos pedaços as ferramentas conceituais do filósofo que possam ser uteis para o nosso trabalho ou, até mesmo, respirarmos cuidadosamente a atmosfera que envolve sua oficina. Em outras palavras, usá-lo aqui, ali e em muitos lugares; mas não necessariamente sempre (VEIGA-NETO, 2006, p. 83).

Considerando essas advertências iniciais é que explicitamos algumas dessas ferramentas a serem utilizadas para problematizar as relações entre educação, eugenia e biopolítica, que no caso brasileiro, será focada no contexto dos anos 1911 a 1945, período importante que abarca o início de um programa de branqueamento da população, a instauração do Estado Novo e sua derrocada em 1945, que coincide com o fim da II Guerra e o silenciamento da raça.

Quando Foucault (1991, p.129) nos apresenta, em Vigiar \& Punir, os regulamentos que instruem a organização das fábricas (oficinas), do exército, do hospital e da escola, nos demonstra que, na realidade, esses regulamentos se destinam a um mesmo fim, possuem um “projeto” em comum e um mesmo princípio: o disciplinar. Princípio que articula o saber e o poder no cerne do que entendemos por sociedade moderna, chamada por ele, de sociedade disciplinar. Segundo Foucault (1991, p.153), “a disciplina ‘fabrica’ indivíduos; ela é a técnica específica de um poder que toma os indivíduos ao mesmo tempo como objetos e como instrumentos de seu exercício”. A educação é, certamente, uma das principais instituições articuladoras do poder-saber que atravessa a constituição dos sujeitos, é uma das instituições estruturantes na construção dos sistemas de "verdade" que articulam os saberes a partir dos quais os sujeitos possam ser objetivados. O dispositivo escolar, nesse sentido, é um legitimador dos discursos sobre a verdade, sobre os "regimes de verdade" que instruem e firmam os parâmetros de governamento dos sujeitos, de sua normalidade e de sua anormalidade. Articula o poder-saber no nível das subjetividades, no nível da capilaridade, implica em considerálo como agenciador das verdades que formam os sujeitos normais, ou melhor, aqueles indivíduos adequados à norma, à prescrição, à normatividade. Sujeitos normalizados de 
acordo com o que se deseja deles (norma), princípio homogeneizador que regula os critérios da normalização, "um assinalamento das diferentes curvas de normalidade” (VEIGA-NETO; LOPES, 2007, p.956). Não se deve entender o poder aqui como um objeto ou estratégia unidirecional de ação, ou ainda, como uma relação linear entre alguém que domina e exerce o poder e os que são alvos desse exercício, concepção clássica da ciência política. O poder para Foucault se situa nas relações entre os homens e não sobre homens. É uma relação informada por saberes que legitimam a ação sobre a ação dos outros sem, contudo, entender essa ação como negativa. O poder, como o autor mostra em Vigiar \& Punir, produz, visa aprimorar e adestrar, quer otimizar (FOUCAULT, 1991). Segundo Jardim (2006, p.104):

O poder é tão produtivo, que através de seu exercício e das configurações que são subjacentes a tal movimento faz surgir novas configurações, novas visibilidades, novos indivíduos-sujeitos enquanto efeitos de uma maquinaria social que envolve todo o tecido social, numa multiplicidade de relações de força.

Esta percepção do indivíduo como sujeito rompe com a visão idealizada do “sujeito” moderno autônomo e cognoscente. Foucault mostra que os sujeitos são o resultado dos saberes e não propriamente seus “autores”. Daí que as condições para que os saberes apareçam e se instituam como verdades que "afetam” os sujeitos implica em considerar o poder. O poder-saber articula essa relação que faz do sujeito um efeito também dos regimes de verdade. Para Veiga-Neto (2003, p. 53), “o sujeito moderno não está na origem dos saberes; ele não é o produtor de saberes, mas, ao contrário, ele é um produto dos saberes”. A educação, na modernidade, cumpre o papel de dispositivo nessa dinâmica, pois,

[...] a educação - saber pedagógico - se instala, portanto, como uma das melhores formas de controlar os discursos de verdade além de ser, também, o meio privilegiado em que saber e poder estão mais explícitos para a implantação de uma técnica institucional: de vigilância, de hierarquia, de disciplina e de controle (JARDIM, 2006, p.105).

A educação disciplinar visa o corpo, quer maximizá-lo e aprimorá-lo, torna-lo um veículo seguro para as práticas de subjetivação. “E o desenvolvimento das práticas pedagógicas é um exemplo claro da produtividade e da positividade do poder quando em suas técnicas, procura aprimorar, adestrar e controlar o corpo do aluno” (JARDIM, 
2006, p.104). O corpo adestrado, regulado, saudável e ajustado à economia do poder é condição para as práticas de constituição da norma e dos processos de normalização. Para Teshainer (2006, p.61), “O poder disciplinar é uma modalidade bem específica da nossa sociedade, é a síntese ente corpo e poder”. Essa relação do poder com o corpo fica clara quando percebemos que o poder disciplinar se organiza a partir de três condições: “a organização do espaço, do tempo e das capacidades” (MARSHALL, 2010, p.24). Esta tríade organiza a vida escolar, estrutura a educação como dispositivo do podersaber e permite que se organizem as estratégias de governamento. A educação, no caso, a instituição escolar (dispositivo), é o espaço por excelência da circulação das verdades sobre o sujeito. Espaço estratégico onde “as normas que são estabelecidas, os exames, as classificações e as punições disciplinares são todos parte dessa noção de governo” (MARSHALL, 2010, p.25).

O poder disciplinar ao focar o indivíduo, ao sujeitá-lo, individualiza-o, permite que se extraia a "verdade" do sujeito, que se faça mobilizar os discursos que o constitui e o normaliza. A economia do poder aqui é efetiva, pois, como mostra Foucault no exemplo clássico do Panóptico, foi essa estratégia de disciplinamento que permitiu que um ou poucos pudessem governar muitos. A “arte” de agir sobre a ação dos outros, de governar, jamais seria possível, na modernidade, sem essa capacidade de mobilização política do corpo, de sua plasticidade e normalização.

Se no nível do indivíduo a disciplina foi a estratégia a partir do qual o podersaber pode ser dinamizado, no nível das coletividades, das massas e multiplicidades humanas, o poder-saber que se instituirá no séc. XVIII em diante será traduzido pelo biopoder. Foucault identifica essa nova forma de consideração das massas no século XVIII, quando, "na modernidade o Estado deixa de ser essencialmente definido pelo território, mas pela massa da população, com seu volume, sua densidade” (VEIGANETO; LOPES, 2007). É justamente quando a população se torna objeto de interesse do poder que nasce uma nova forma de governamento, de poder-saber sobre as multiplicidades humanas, que Foucault vai chamar de biopoder, traduzida no campo do governo como biopolítica. Segundo Branco (2008, p.85),

[...] a era do biopoder ou da biopolítica da espécie humana é posterior e complementar ao desenvolvimento das técnicas disciplinares, que ocorreram nos séculos XVII e XVIII, e que se dirigiam, em especial, ao mundo do trabalho. Enquanto nas técnicas disciplinares as questões eram o corpo, suas aptidões e capacidades de adestramento, os problemas, para a biopolítica, o que importa passa a ser temas como a 
fecundidade, a morbidade, a higiene ou saúde pública, a segurança social, etc.

Esse é o contexto em que a espécie humana se torna objeto de investigação e intervenção política. "Deslocamento do poder-saber do corpo-máquina para o corpoespécie” (PELBART, 2011, p.57). As condições de possibilidade para que a eugenia surgisse como manifestação do biopoder estavam postas. Para Pelbart (2011, p.59), “se o racismo existia muito antes do surgimento do biopoder, foi este o responsável pela introdução do racismo nos mecanismos de Estado, e como mecanismo fundamental do Estado”. A população passou a ser considerada na sua constituição biológica e o Estado tratou de ajustar as estratégias de governo a partir de outas formas de governamento, de novos regimes de verdade sobre a vida e, ainda, sobre a raça. A eugenia será a ciência da espécie humana, considerada na sua diversidade racial. Será o saber da intervenção, inflexão sobre os desejados e indesejados, os eugênicos e disgênicos, os (bio)anormais, os que merecem ou não viver/procriar. “O que está em jogo é a gestão da vida e a administração dos fenômenos biológicos do homem-espécie” (BRANCO, 2008, p.86). A eugenia, como saber sobre a espécie e sobre as raças, atinge o corpo e revela suas verdades intrínsecas, inatas e biodeterminadas. Os processos de normalização são agora construídos a partir dos parâmetros biológicos e a eugenia será o dispositivo de intervenção que avalia, examina e determina quem contribui ou não para a melhoria e especialização da espécie. Os dispositivos normalizadores, como é o caso da educação, ou melhor, da instituição escola, terão na verdade da raça novos aportes para a construção de sujeitos eugênicos.

Esses sujeitos eugênicos, formadores de uma coletividade, igualmente eugenizada, no entanto, serão o resultado de uma intervenção na sexualidade. A eugenia, enquanto desdobramento de estratégias biopolíticas, visa intervir diretamente no corpo dos sujeitos, no corpo-espécie, a partir do qual certa coletividade pode vir a ser normalizada e regulada. A norma, no caso, a raça eugenizada, livre das interferências disgênicas, seja pela hereditariedade ou vícios sociais, é o objetivo maior da "ciência" ou mesmo "religião” eugênica. Para tanto, dois vieses de intervenção são constituídos, a intervenção direta e invasiva no corpo dos sujeitos, chamada eugenia negativa, ou através da profilaxia, tendo como veículos efetivos a educação e a propaganda. Seja pela esterilização, proibição de casamentos e castrações como na eugenia negativa, ou pela orientação sexual e exames pré-nupciais, como no caso da positiva, a eugenia 
aponta para o campo de intervenção à sexualidade. A sexualidade é o fio condutor de gestão eugênica, até porque a regulação das relações sexuais, a escolha de parceiros e, por consequência, a procriação, constituem a base a partir da qual a coletividade, enquanto espécie é construída (FOUCAULT, 2001). Trata-se de estratégia biopolítica, que tem na sexualidade seu dispositivo mais efetivo. Segundo Pelbart (2011, p.58),

\begin{abstract}
A sexualidade encontra-se precisamente nesse entrecruzamento entre os dois eixos da tecnologia política da vida, a do indivíduo e da espécie, a do adestramento dos corpos e a regulação das populações, a dos controles infinitesimais, o micropoder sobre o corpo e as medidas massivas, estimações estatísticas, intervenções que visam o corpo social como um todo.
\end{abstract}

A sexualidade enquanto dispositivo se inscreve nesse campo da política da vida, campo de intervenção biopolítico, quando o Estado toma pra si a responsabilidade de intervir no corpo espécie da população. Para Pelbert (2011, p.58), “de fato, o sexo faz a ponte entre o corpo e a população, a tal ponto que o que era da sociedade do sangue, corresponde ao poder de soberania, na era do biopoder torna-se do sexo”.

O biopoder se situa no contexto da governamentalização do Estado, num contexto pós-soberania, ou mesmo, num período de deslocamento da esfera jurídica de legitimação das ações soberanas para a sociedade que tem na racionalização da gestão do Estado sua base. Dito de outra forma, uma sociedade que independe do soberano, que está articulada na distribuição da gestão por todo o “corpo” social, na potenciação da burocracia e gestão públicas, racionalização e governamentalização do próprio Estado.

\title{
Considerações iniciais sobre eugenia
}

A eugenia é, sem dúvida, o mais significativo acontecimento biopolítico do séc. XIX. Como um desaguar das teses racialistas e dos delírios de pureza que engendraram as narrativas nacionalistas do séc. XIX, a eugenia enquanto programa de Estado se tornou um paradigma praticamente universalizado no ocidente, e, sua infâmia, só foi possível, ainda que não definitivamente, após os acontecimentos sombrios levados a cabo pelo Nacional Socialismo (BLACK, 2003; CENTURIÃO, 2009).

Como campo de conhecimento e intervenção biopolítica, a eugenia tem no século XIX suas bases demarcadas significativamente a partir da publicação de uma 
série de obras que visavam responder as interrogações sobre a diversidade humana. Destaca-se, nesse contexto, o célebre Ensaio sobre a desigualdade das raças humanas (1858), de Conde Joseph Arthur de Gobineau (1816-1882), onde o autor propunha uma história universal baseada no determinismo racial. O arianismo da obra, a condenação da miscigenação e o proselitismo da superioridade racial dos brancos (leia-se arianos), percorrem toda reflexão de Gobineau. Este tipo de reflexão, no entanto, carecia de base científica, segundo os preceitos da época, o que não diminuía, de fato, o alcance “social” de tais proposições. Um ano após a publicação do Ensaio de Gobineau, veio a público a obra maestra de Darwin, The Origines of species (1859), onde não só uma verdadeira síntese teórica da evolução é apresentada, mas, ainda, a “descoberta” da “chave" que dava conta dos mecanismos desse processo. Foi em Malthus que Darwin percebeu que a luta dos mais aptos (fortes) gerava a lógica evolutiva em determinado espaço-tempo, o que permitia explicar satisfatoriamente a genealogia das espécies. Esse texto que, é preciso lembrar, não trata da Eugenia nem propõe uma reflexão focada no homem, se constitui, doravante, na matriz biodeterminista que passou a ser utilizada para fundamentar uma série de teses e hipóteses racialistas.

Se Darwin descobriu os “segredos” da evolução, ele não chegou a formular, entretanto, a ideia de eugenia, pelo menos nesse contexto da metade do século XIX. É preciso considerar, contudo, que a síntese evolutiva que a obra de Darwin promoveu abria novos horizontes especulativos sobre a chamada "perfectibilidade humana”. Se a natureza tinha uma lógica própria que cumpria os desígnios da evolução e sobrevivência dos mais aptos, a história do homem revelava os desvios do caminho, a rasura da lógica natural. Destinava-se à ciência, então, reparar esses erros e colocar o homem no devido caminho da perfectibilidade. Coube à tarefa de teorizar sobre essa ciência da correção e aperfeiçoamento espécie humana, ao sobrinho de Darwin, Francis Galton. O conceito de eugenia aparece, pela primeira vez, na obra de Galton (1869), Hereditary Genius. A partir da ideia de que a "raça” humana estava em constante evolução, Galton pensava que era papel da ciência e das políticas públicas acelerar essa evolução e assim contribuir para o aperfeiçoamento desse processo com a criação de humanos geneticamente superiores.

O movimento eugênico nasce desse triunfo do biodeterminismo, e a raça surge como chave da história e estratégia política num período marcado pela expansão das potências europeias nos territórios africano e asiático. No âmbito do Estado-Nação oitocentista, a raça triunfou também como cimento constitutivo das identidades 
nacionais, funcionando como elemento naturalizador da cultura. No caso do arianismo, por exemplo, o triunfalismo foi de tal monta que o antropólogo britânico Chamberlain, autor da obra, de 1899, Os fundamentos do século XIX (Die Grundlagen des neunzehnten Jahrhunderts), que lhe valeu a alcunha de antropólogo do Kaiser, chegou a abandonar sua nacionalidade pela alemã.

Até o final do século XIX, no entanto, faltava para a eugenia a "mecânica” de intervenção hereditária. Essa veio em 1900 com a redescoberta e publicação das leis de Gregor Mendel (1822-1884). A partir daí, a eugenia ganhava, efetivamente, autoridade científica, pois, com Mendel a hereditariedade tornou-se conhecida e seus mecanismos “passíveis” de manipulação. Os planejadores sociais podiam atuar amparados pelas teorias do inativismo/hereditariedade e com isso institucionalizar princípios eugenistas. As teorias de Mendel sobre estabilidade dos caracteres transmitidos de geração a geração, somadas as contribuições de Weismann acerca da continuidade do plasma germinativo, definiram um campo empiricamente viável do ponto de vista científico, que servira de base para os eugenistas.

Consolidava-se a base de uma nova épistémè, sobre a qual uma nova forma de governamento se instituiria. E essa forma de governamento iria ser fundamental para a consolidação das narrativas nacionais, cujos desdobramentos mais radicais encontramos na II Guerra.

O prestígio da eugenia fica evidente quando observamos a criação de inúmeras “sociedades” dedicadas a sua divulgação e implementação. Destacam-se as sociedades eugênicas na Alemanha (1905), Inglaterra (1907), Estados Unidos (1910), França (1912), entre outros (DE LUCA, 1999, p.153). Merece lembrança ainda a criação, em 1912, do Comitê Internacional de Eugenia, dirigido pelos norte-americanos.

As políticas eugenistas tiveram largo espectro e entre seus métodos preferidos, junto à esterilização, estava a regulação da reprodução da espécie a partir do controle dos casamentos. Procurava-se evitar as uniões disgênicas ou, quando não era possível, esterilizar um dos chamados “anormais”. O próprio Galton propôs modelos de legislação eugênica no texto Restriction in marriage, onde defendia ações políticas para conter a proliferação de tipos disgênicos (GALTON, 1905).

Em que pese a eugenia ter "nascido” na Europa, nomeadamente na Inglaterra, foi nos EUA que ela passou a orientar pioneiramente as políticas racialistas de interdição dos anormais. Segundo Nancy Stepan (2005, p.38), “pelo final da década de 1920, 24 estados americanos haviam aprovado leis que previam esterilização 
involuntária, que foram aplicadas principalmente a internos pobres (e geralmente negros) das instituições para débeis mentais”. No final do século XIX, nomeadamente em 1895, o alemão Alfred Ploetz publicou a obra The Foundations of Racial Hygiene, onde já propunha as estratégias eugenistas para a raça alemã, contudo, fora o movimento eugenista legislativo dos EUA que acabou por servir de modelo aos eugenistas alemães. O modelo norte-americano foi amplamente estudado na Alemanhã dos anos 1920 e levado a cabo pelo III Reich logo após a derrubada da República de Weimar.

Nos EUA, país modelar no que se refere aos programas eugênicos, as bases teóricas que fundamentaram as políticas racistas podem ser mensuradas a partir de autores como Madison Grant e Theodore Lothrop Stoddard. Grant, o maior expoente do eugenismo norte-americano, foi curador do American Museum of Natural History e sua influência na legislação imigrantista foi notável a partir da obra The Passing of The Great Race; or, The racial basis of European history (1916), que repercutiu nas leis The Immigration Act e Asian Exclusion Act, de 1924 (BLACK, 2003). Essa obra de Grant vendeu 1.600.000 cópias até 1937, o que demonstra a importância de sua atuação nos EUA. Stoddard foi um dos grandes justificadores da eugenia nos EUA e publicou diversas obras sobre o tema entre 1914 e 1940. Na obra The Rising Tide of Color: Against White World-Supremacy, de 1922, constrói a estereotipia do negro norteamericano, fundamentada nas teses da segunda metade do século XIX. Para Stoddard (1922),

O homem negro é, na realidade, fortemente diferenciado de outros tipos humanos. Sua maior característica é a superabundante vitalidade animal. E nisso ele ultrapassa as outras raças. A isso ele deve a sua intensa emoção. E isso, novamente, é devido a sua extrema fecundidade, o negro é o mais rápido dos reprodutores. Esta abundante vitalidade se mostra entre muitas outras coisas, tais como, habilidade do negro de sobreviver em condições duras de escravidão sob as quais outras raças teriam sucumbido.

Vários países europeus, sobretudo os nórdicos, implementaram leis eugênicas, como é o caso da Suíça (1928) e Dinamarca (1929), que esterilizaram aproximadamente 8.500 pessoas entre 1930 e 1939 (DE LUCA, 1999, p.153). Segundo De Luca (1999, p.153), no entanto, "nenhum Estado foi tão longe quanto o nazista, cujo tribunal especial de saúde genética supervisionou a esterilização compulsória de cerca de 1\% de toda a população do país”. 
A miscigenação, nessa direção, era a contradição evidente da lógica nacional. A mistura das raças não só corrompia o homem, sobretudo o branco, mas também, o próprio Estado-nação, obstruído no seu objetivo de homogeneização da população. Entende-se porque os teóricos racialistas, como Gobineau, se horrorizavam com a nação brasileira. O Brasil representava o laboratório mais perfeito dos malefícios da mistura das raças no processo civilizatório.

\section{Caminhos da Eugenia no Brasil}

O Brasil acompanhou as discussões acerca das teses darwinistas/evolucionistas desde o último quartel do século XIX, haja vista a receptividade da chamada "Escola de Recife” e da Escola de Medicina da Bahia. A eugenia, por aqui, no entanto, andou pari passu com outro movimento significativo na primeira república, o sanitarista. Não se pode, ainda, considerar que haja coerência ou mesmo um viés comum entre os sanitaristas-eugenistas brasileiros no período. É preciso considerar ainda, quando analisamos o movimento higienista-eugenista nacional, que não se institucionalizou uma política de eugenia negativa, em que pese vários teóricos terem assumido a defesa de tais medidas, como veremos abaixo.

A questão racial que havia norteado as narrativas identitárias europeias, no caso brasileiro, precisa ser entendida em suas especificidades, pois, a miscigenação da população colocava problemas intransponíveis para o discurso eugenista, entendido nos moldes europeus. O caso do Brasil, assim como o de Portugal e da maioria dos países latinos e católicos, de acordo com a tese de Ana Leonor Pereira (2001), a eugenia não se constituiu como um projeto nacional definido e instrumentalizado, o que não significa que na América Latina o movimento não tenha seus momentos significativos. Não se pode, ainda, considerar todos os países da América Latina como participantes de um movimento homogêneo, como chama a atenção Nancy Stephan (2005). Fica claro, portanto, que generalizações não são aceitáveis quando nos debruçamos sobre o movimento eugenista na América Latina.

O movimento eugenista no Brasil, como chamamos a atenção acima, precisa ser entendido através das suas profundas relações com o higienismo, mesmo que ambos tenham como foco objetos e objetivos diferentes. Segundo Tânia De Luca (1999, p. 223), 
abstinência de toxinas, da vida ao ar livre, da adoção de hábitos higiênicos; já a segunda (eugenia) pretendia, com base nos conhecimentos acumulados a respeito da reprodução humana, aperfeiçoar física e moralmente a espécie.

Assistimos no país uma significativa influência do discurso eugênico entre intelectuais, “cientistas” e juristas da época, como atestam as associações, clubes, publicações e diversas conferências proferidas por “eméritos” entusiastas como Renato Kehl (1923) e Octávio Domingues (1938).

O início do movimento no Brasil remonta ao final do século XIX, em que pese não ter sido ainda plenamente explicitado, e via na questão das misturas raciais o maior problema para a construção civilizatória do país. A miscigenação era em si considerada disgênica e um caminho aberto para todos os males da vida cotidiana, e, acima de tudo, para a construção da nação. Na célebre frase do professor de direito criminal Laurindo Leão (apud SCHWARCZ, 1993, p.167), “uma nação mestiça é uma nação invadida por criminosos”. Para Nina Rodrigues (1894, p.161-162), representante maior da chamada Escola de Medicina da Bahia, “mesmo nos mestiços mais disfarçados, naquelles em que o predominio dos caracteres da raça superior parece definitiva e solidamente firmado, não é impossivel revelar-se de um momento para outro o fundo atavico do selvagem”.

Até os primeiros anos da República a miscigenação era vista como um problema nacional que urgia ser considerado pelos teóricos da cultura bem como pelos governantes. A “solução” eugênica nacional recolocou o debate sobre a miscigenação noutros termos menos ortodoxos. A mistura de raças que outrora condenava a civilização brasileira, como em Nina Rodrigues, passou a ser, a partir do início do séc. XX, uma saída eugênica. Um acontecimento marca essa heterodoxia. Em 1911 o Brasil envia para Congresso Universal das Raças, realizado em Londres, o cientista Batista de Lacerda (1846-1915), que profere uma famosa conferência em que defende a miscigenação como meio de superação do problema do negro na composição social do povo brasileiro. Batista de Lacerda, segundo Lilia Schwarcz (2011, p.226), “era pessoa certa para tomar parte de evento de tal importância. Afinal, combinava várias especialidades, entre elas a antropologia e, ainda mais, dominava as potencialidades de um país de raças mistas como o Brasil”. E foi justamente a problemática da miscigenação que Lacerda abordou em sua conferência, uma abordagem que procurava demonstrar as especificidades das misturas raciais e seus efeitos na construção histórica no Brasil. Seguindo a agenda do evento, em que cada país participante trataria de expor 
situações específicas de suas nações, Lacerda, nesse sentido, contrastou o Brasil com os países latino-americanos e com os EUA e, o que era um tanto inusitado na época, positivou as misturas raciais para um futuro próspero da nação. Segundo Schwarcz (2011, p. 227), que analisou a conferência de Batista de Lacerda e a traz como anexo em seu estudo,

Em primeiro lugar, o cientista defenderia a concepção de que o Brasil não se igualava às demais 'republiquetas vizinhas' e que, ao contrário, por aqui reinaria a mais sublime ordem. Em segundo lugar, era necessário defender o mais difícil: a mestiçagem brasileira seria (apenas) transitória e benéfica, uma vez que não deixaria rastros ou pistas. Mais ainda: era preciso demonstrar como nos portávamos de maneira alternativa, até mesmo em relação aos EUA. Se por lá grassara um sistema escravocrata violento, no Brasil o processo teria sido marcadamente pacífico. Além do mais, se na América do Norte vigia uma ampla gama de preconceitos, por aqui a característica mais marcante seria a ausência de padrões de exclusão.

Trata-se do projeto de branqueamento da nação, solução eugênica heterodoxa objetivada a partir de um recurso disgênico, conforme a doxa corrente dos eugenistas europeus e norte-americanos.

O branqueamento era assim uma solução que revelava também a heterogeneidade das posturas eugênicas nos trópicos, uma tradução teórica paradoxal, mas que demonstrava também um debate sobre a identidade nacional que procurava equacionar a conformação da população, diversa e mestiça, com as teorias raciais da época. Octávio Domingues, em artigo para a Revista do Brasil, em 1938, questionava os princípios puristas de uma política eugênica para uma nação mestiça e invertia o axioma da pureza racial, como sustentado pelos eugenistas norte-americanos ou europeus. Segundo ele:

A um exame ligeiro parecerá inconciliável a eugenia com o processo de povoamento vigente no Brasil: mestiçagem. Digo isso porque a propaganda eugênica, no mundo, tem sido orientada ultimamente no sentido de ligar a idea de pureza racial á idea de eugenia. Ora, se nos falta demais a pureza ethnica, porque somos um caldeamento nunca visto na história, lógico será o inferir-se a impossibilidade de applicação das sancções eugênicas entre nós. Não se comprehende eugenia com raça pura. (DOMINGUES, 1938, p. 308).

Na continuação, Domingues (1938, p. 308) afirmava que 
essa conclusão, aliás natural em face do racismo divulgado aos quatro ventos, é exaggerada, para não dizer errônea. Pode-se mesmo affirmar que, no nosso caso, a eugenia seria até mais indicada, porque muito maior é a variabilidade genética da população.

Contrastava com as ideias de Domingues as teses de Renato Kehl que, entre todos os eugenistas brasileiros, merece destaque pelo seu entusiasmo e dedicação incansável na divulgação da eugenia. Kehl foi fundador da primeira sociedade eugênica da América Latina, a Sociedade Eugênica de São Paulo (1917). Belisário Penna, coautor com Artur Neiva (1999) da célebre Viagem Científica, em prefácio a obra de Kehl, Eugenia e Medicina Social, sintetiza o projeto do eugenista:

Pois bem, nada disso será uma realidade [o gozo máximo da vida], emquanto o homem, á semelhança do que pratica com os animaes e as plantas, não se dispuzer a aperfeiçoar-se physica, intellectual e moralmente, creando o typo equilibrado da especie, expurgando dos defeitos e das taras morbidas que se vêm accumulando desde a origem da humanidade. É ao que se propõe a sciencia eugenica ou Eugenía, o aperfeiçoamento da espécie. (PENNA, 1923, p. II-III)

Frente às precárias condições sanitárias do país, os eugenistas brasileiros atentavam, sobretudo, para o higienismo, para a eugenia preventiva, que na percepção de Belisário Penna era a verdadeira Medicina Social. Para ele a higiene era a “precursora no aperfeiçoamento da humanidade” (PENNA, 1923, p.IV). Kehl (1920 apud SOUZA, 2006, p. 55) fazia eco à postura de higienistas como Belisário Penna, pelo menos no início de sua empreitada eugênico-higienista. Para ele,

Podemos dizer, sem medo de controvérsias, que o Brasil é constituído, na sua quase totalidade, de gente doente ou em franca degeneração. Esse grito de alarme levantado pelo professor Miguel Pereira, Belisário Penna e outros em prol do saneamento do nosso 'hinterland' não significa o sertão de Goiás, nem o de Mato Grosso. É quase todo o Brasil, a começar pelos subúrbios dessa capital.

Souza, ao analisar a primeira fase de intervenção de Renato Kehl em prol da eugenia no Brasil, destaca essa postura mais voltada a higienia e ao sanitarismo, na linha de Belisário, postura que mudará na direção de uma eugenia mais negativa nos anos 1930.

O autor chama a atenção para a atuação de Kehl na difusão e na propaganda eugenista no Brasil. Segundo ele, “era necessário tornar a eugenia uma doutrina popular 
para só depois vê-la transformada em projeto, leis e manuais escolares” (SOUZA, 2006, p.47).

O necessário esclarecimento e difusão/popularização dos preceitos eugenistas eram condição sine qua non para o avanço de uma perspectiva eugênica. A aposta dos eugenistas como Kehl e entusiastas como Monteiro Lobato, entre outros, era na “Educação Eugênica”. Os manuais escolares, bem como a literatura infantil, deveriam constituir o veículo de pedagogização eugênica no Brasil. Daí o investimento em conferências em escolas e instituições educacionais, a publicação em jornais e livros de acesso mais amplo da população escolar. A publicação do Boletim de Eugenia, editado entre 1929 e 1933 por Renato Kehl, tinha por objetivo, além de servir como propaganda para o Instituto Brasileiro de Eugenia, difundir os princípios eugênicos entre os brasileiros. Era uma publicação de caráter pedagógico. Daí que “um dos temas tratados por diversos autores que escreveram no Boletim de Eugenia foi à educação” (ROCHA, 2011, p.166).

Durante os anos 1920 temos uma série de reformas educacionais no país que atendiam também os preceitos higienistas: “São Paulo (1920), Ceará (1922-1923), Bahia (1928), Minas Gerais (1927-1928), Pernambuco (1928), Paraná (1927-1928), Rio Grande do Norte (1925-1928) e Distrito Federal (1922-1926)” (GADELHA, 2009, p.189). Essas reformas acabaram por impulsionar, em 1931, a criação do Ministério da Educação e Saúde que, entre outras ações, pretendia a unificação do sistema de ensino nacional. O próprio nome do Ministério sugere essa estreita relação entre higienismo, leia-se também eugenismo, e educação. Não é sem sentido que o primeiro ministro tenha sido um simpatizante do fascismo, Francisco Campos, que, segundo Gadelha (2009, p.190), orientava “diversas de suas iniciativas de acordo com o que acontecia na Itália de Mussolini”. É a esta relação entre a biopolítica eugênica e a educação que nos deteremos a seguir.

\section{O discurso eugênico, biopolítica e Educação no Brasil}

No Brasil, como vimos acima, a eugenia que prevaleceu foi a positiva. Não se tratou de uma opção puramente política, tendo-se em vista que, na realidade, o caso brasileiro impunha um desafio à ciência de Galton. O problema da “raça” era, de fato, complexo para “soluções” ortodoxas, pelo menos a curto ou médio prazo. A positivação da miscigenação como vetor eugênico é inusitada, mas sustentou um movimento importante e com desdobramentos efetivos na construção da nacionalidade a partir do 
início do século XX. Por outro lado, sendo a eugenia positiva a opção dos “cientistas” da época, pois era evidente a incapacidade de construir uma ciência puramente eugênica, frente aos “apelos” consideráveis do higienismo, o caminho trilhado era o da educação e da propaganda eugênica. Era necessário tratar “esse” povo doente, esse “imenso hospital”, no dizer de Miguel Pereira, para daí sim colocar as preocupações clássicas da eugenia na agenda política. Daí a propaganda e educação eugênicas se tornarem enfáticas no movimento. Eugenia e higienia se tornaram inseparáveis o que, de certo modo, forçou a uma relativização do biodeterminismo, pois, como fica evidente no conjunto do discurso dos eugenistas-higienistas, o problema maior do Brasil era “médico".

A educação era a “arma” mais poderosa de divulgação e implementação de políticas higienista-eugenistas no país. Educação e Eugenia foi o título da conferência de abertura do Congresso Eugênico Brasileiro (1929), proferida por Levi Carneiro (1929, p.115), onde defendia a educação como meio de intervenção eugênica. Estava claro, inclusive observado outras manifestações no Congresso, que era preciso uma estratégia pedagógica para que a eugenia fosse possível nessas terras mestiças e doentes.

Se a miscigenação, como vimos, fora positivada, considerando as condições seletivas da imigração, por outro lado, se defendia uma prevenção à miscigenação para aqueles que pudessem ser considerados sujeitos eugênicos. Para Rocha (2011, p.172), “era preciso educar para os fins eugênicos”, conscientizar sobre o "perigo da miscigenação e priorizar a educação dos indivíduos que traziam hereditariamente um potencial de habilidades comuns a sua linhagem”.

Era, como fica evidente, o dispositivo da sexualidade que se acionava e se delineava, política de proteção familiar, de orientação de condutas. É evidente, nessa proposição de cuidado com a sexualidade e com a família a estratégia de gestão biopolítica. Para Gustavo Capanema, segundo a ocupar a pasta do Ministério da Educação e Cultura, “constituída pelo casamento indissolúvel, a família era a base da organização social brasileira, demandando, portanto, que fosse colocada sob proteção especial do Estado” (GADELHA, 2009, p.194).

Renato Kehl (1923), em Lições de Eugenia, defendia uma educação formadora de uma consciência eugênica, destacando a orientação sexual. Segundo Rocha (2011, p.169), 
A finalidade da educação segundo Kehl seria evitar a má formação e a ignorância por parte dos estudantes sobre orientação sexual, relações conjugais e criação dos filhos. As meninas deveriam ser preparadas para as futuras obrigações do lar e da maternidade, compreendendo a nobreza de uma maternidade sadia onde as boas características seriam transmitidas às futuras gerações.

É o dispositivo da sexualidade que era pensado como viés educativo, moralizante e disciplinador das condutas sociais. Relacionar o sexo com os comportamentos era, de fato, mapear todo um conjunto de atitudes contraproducentes. Era preciso normalizar os sujeitos e preparar o caminho para uma moralidade eugênica. Conforme Rocha (2011, p.171),

\begin{abstract}
Pode-se dizer que as reformas educativas criadas neste período tiveram no ideal de formação eugênica uma proposta moral, de bons costumes e melhorias no condicionamento físico, visto este fator ser de ordem significativa para a formação de uma raça fisicamente forte, com padrões estéticos que definiriam segundo os parâmetros eugenistas, a nobreza de uma raça.
\end{abstract}

Dentre as disciplinas escolares, a Educação Física, era a privilegiada, pois visava o corpo do indivíduo e, por desdobramento, propiciava uma educação comportamental e moralizante das condutas sociais.

Na Constituição de 1934, no artigo 138, a educação eugênica era oficialmente reconhecida: “Art 138 - Incumbe à União, aos Estados e aos Municípios, nos termos das leis respectivas. b) estimular a educação eugênica” (BRASIL, 1934). Da mesma forma, a Constituição de 1937, no artigo 131, se refere à educação eugênica, situando a educação Física como disciplina estratégica: “Art 131 - A educação física, o ensino cívico e o de trabalhos manuais serão obrigatórios em todas as escolas primárias, normais e secundárias, não podendo nenhuma escola de qualquer desses graus ser autorizada ou reconhecida sem que satisfaça aquela exigência” (BRASIL, 1937).

O processo de legitimação da disciplina Educação Física no Brasil é coevo ao movimento higienista/eugenista e contou com a sistemática defesa de seus atributos na melhoria da população. Como meio de difusão dos princípios que norteavam a disciplina, seu caráter científico e pedagógico, destaca-se a publicação, entre 1932 e 1945, da revista Educação Physica. Importantes intelectuais da época publicaram na Revista, com destaque para Renato Kehl, Hollanda Loyola, editor do periódico, e Fernando de Azevedo, este último autor da obra Cultura Brasileira. 
Fernando de Azevedo era um entusiasta da educação física, inclusive discorrendo sobre a importância dessa disciplina em outras obras bem como na revista Educação Physica. Na obra Da Educação Physica. O que ella é, o que tem sido, o que deveria ser, publicada em 1920, Azevedo (1920 apud CHAVES, 2001) considerava que “A educação physica scientificamente fundamentada torna-se por este modo maravilhoso instrumento de transformação social ethnica, com a realização de amplissimo objectivo".

Mendes e Nobrega destacam nessa obra a seguinte manifestação de Fernando de Azevedo, que permite entender as bases “científicas” que sustentavam sua defesa eugênica da educação física. Azevedo lançava mão do Lamarckismo, ou melhor, da tese dos caracteres adquiridos, em que pese às críticas já consolidadas a este suporte teórico. Para ele, a partir da educação física:

Era possível alcançar o necessário para a regeneração da raça, já que caracteres selecionados poderiam ser herdados pelos filhos. O argumento também era um dos trunfos de Fernando de Azevedo para justificar os méritos da educação física nesse período: O exercicio esta maravilhosa acção mecânica, é que corrige e modela a estructura humana. Quando, pois, persistindo a causa durante varias gerações, a herança fixa definitivamente os caracteres adquiridos, as modificações anatômicas assim produzidas tornam-se permanentes e chegam á constituição de espécies novas, de maneira que uma adaptação a uma funcção útil póde definitivamente fixar-se sob fórma de um caracter ethnico, assim como a atrophia de certos órgãos póde chegar ao desapparecimento ethnico. (AZEVEDO, 1920 apud MENDES; NOBREGA, 2008, p.214-215).

Num artigo publicado em 1936 na revista Educação Physica, Fernando de Azevedo utilizava o exemplo “concreto" do caso da Inglaterra para comprovar sua postura. Dizia ele sobre os tipos humanos no tempo de Carlos IV, observados nas estampas da época:

[...] um bom burguez, de ventre proeminente quase sempre obeso, a fumar sem preocupações, seu cachimbo. O typo atual não é mesmo. Esta raça se modificara completamente no decorrer do último século, e não me parece incorrer em exagero declarando que esta feliz modificação é devido ao esporte, que permitiu aos anglo-saxões, na luta contra o alcoolismo e a tuberculose, restaurar a medida da raça (AZEVEDO, 1936, p.12).

Na mesma direção considerava, sobre, os EUA, que: 
A creação do typo americano por transformação progressiva do typo inglez primitivamente invasor, é mais um exemplo frisante destas regras endo-technicas, pelas quaes transportados a um meio diferente, submetido a outro regimen alimentar e sob a influência depurativa e apuradora do exercício, tende o typo éthnico primitivo a modificar-se apresentando modelos anthropologicos de personalidades, inconfundíveis e, na architectura somática e nas tendências psychicas, perfeitamente discriminadas daqueles typos ethnicos, que o produziram (AZEVEDO, 1936, p.12-13).

A conclusão lamarckista de Azevedo (1936, p.14), considerando os exemplos acima, é enfaticamente afirmada na seguinte passagem do artigo:

As gerações de amanhã apuradas, por 'systema', pela educação physica - afinadora da raça e colaboradora do progresso imprimiriam assim, nas que lhes sucedessem, o cunho de seu caráter, para que pudessem, com o argumento do patrimônio biológico hereditário, aperfeiçoar ainda mais a natureza humana.

No editorial de 1937, o papel eugênico da disciplina Educação Física fica explícito: “Um paiz vasto como o nosso, com o typo racial ainda por definir-se, sob o afluxo de vários factores, á intercorrência de elementos diversos, necessita, obrigatoriamente da educação physica e deve cuidar, com o mais vivo interesse, da eugenia do homem” (EDITORIAL, 1937, p.11).

O papel da Educação Física na construção do povo eugenizado fica evidente em vários textos publicados na revista. Tratava-se de um projeto pedagógico que articulava o saber higienista-eugênico com a política de estado, no caso a educacional, que visava a conformação do corpo-espécie da população. Danailof (2005, p.31) chama a atenção, nesse sentido, que "o diálogo entre Educação Física e higiene apresentava-se a todo o momento ancorado pela preocupação com o futuro, com o progresso e o desenvolvimento do país”, leia-se da nação, do povo que até então era considerado na sua impossibilidade civilizatória.

O exemplo do nacional-socialismo é coroado como modelar, haja vista as ações eugenistas efetivamente implementadas na Alemanhã e a defesa da raça e da nação que estavam implicadas em tal política. Tenorio D’Albuquerque num texto dedicado ao papel da educação física no programa eugenista alemão afirmava, em 1937 na revista:

Em nenhum paiz do mundo, a educação physica esta merecendo tanta attenção por parte do governo, a eugenia do povo preocupa tanto os 
dirigentes nem os sports estão mais bem regulamentados do que na Allemanhã. O Nacional Socialismo, com seu programma de rejuvenescimento da Allemanhã, encarou, como um dos elementos primaciaes para a constituição das nacionalidades, a eugenia do povo, o aprimoramento racial, partindo do principio de que 'não há paiz forte com um povo fraco’ (D’ALBUQUERQUE, 1937, p.18).

A educação física, como a educação de modo geral, deveria estar engajada nesse projeto de higienização social, de aperfeiçoamento moral e racial da população. Educação que atingia o corpo do indivíduo, corrigia suas posturas, sua higiene e suas condutas e, por outro lado, atingia a população, entendida como corpo-espécie, através das estratégias de governamento biopolítico, o que produziria sentido para a criação da nacionalidade. Atuar na homogeneização e no controle das multiplicidades, eis onde a governamentalidade biopolítica se articula na constituição da população.

A miscigenação como aliada no processo de construção do corpo-espécie da população no Brasil, como queriam os eugenistas, implicava no governo da sexualidade. A construção de regimes de verdade que orientassem a sexualidade está relacionada a uma estratégia biopolítica, que toma a população como espécie e a partir dela visa conformar um povo para a nação. Os regimes de verdade, segundo Foucault (2010, p.77), “estão ligados a regimes políticos, jurídicos, etc”. Os regimes de verdade ligam o político ao epistemológico, e fazem com que os homens se manifestem a si mesmos como objeto da verdade. Eis aqui a forma como se governa a si e aos outros a partir de processos de subjetivação que constituem os sujeitos como assujeitados. Nesse sentido é que Foucault (2010, p.66) questiona: "por que o poder, e isso desde milênios em nossa sociedade, exige que os indivíduos digam não somente “eu obedeço”, mas lhes exige ainda que digam: 'eis aquilo que eu sou, eu que obedeço; eis o que eu sou, eis o que eu quero, eis o que eu faço"”. Segundo Nilo Avelino (2010, p.24), “é no momento em que somos chamados a nos constituir como Sujeito que aceitamos o império dos discursos científicos e não-científicos que têm por função revelar aquilo o que verdadeiramente somos”. Não podemos perder de vista que esse movimento todo está contextualizado no âmbito de discussões sobre a identidade nacional, que, vale lembrar, era condição fundamental para a construção do ideário unitarista e homogeneizador estado-novista. Quando, no governo Vargas, se assume a miscigenação como a porte para a identidade nacional, se institui, na mesma ordem, a chamada "ideologia” da “democracia racial” como biopolítica no Estado Novo. Ao institucionalizar a miscigenação como elemento importante na construção da nação, o Estado tomou pra si 
a missão de conferir à “identidade nacional” uma nova narrativa legitimadora, fundante de uma característica que a singularizaria internacionalmente, qual seja, a "democracia racial” e a inexistência do conflito racial. Isso implicou numa nova forma de positivação do povo brasileiro em que a diversidade deveria ser subsumida em nome de uma população-espécie constituída em sua homogeneização futura (branqueamento), mas com anulação dos possíveis conflitos ou contrastes raciais no presente (dos anos 1930). Ao colocar a educação como estratégia de governamento, o movimento eugenista alcançava as famílias a partir de dispositivos disciplinares, adentrando num espaço até há pouco considerado soberano. A educação, nesse sentido, contribuía para a prevenção da saúde pública bem como para a preservação dos bem nascidos ou ainda para a melhoria dos a serem normalizados. É, nesse sentido, que a educação foi um dos principais pilares do movimento higienista-eugenista no Brasil, investimento na infância significava investimento no futuro. E mais, a infância era a porta de entrada para as famílias, meio considerado fundamental para a construção de adultos melhores/controlados/objetivados no futuro. O governamento da família através dos cuidados com a infância ou da puericultura visava à criação de uma “cultura” eugênica, e a educação, ou melhor, o dispositivo escolar, era o espaço privilegiado dessa intervenção biopolítica.

\title{
BIOPOLITICS, EUGENICS AND EDUCATION IN BRAZIL (1911-1945)
}

\begin{abstract}
The article aims to analyze the relationship between education and biopolitics in Brazil between 1911 and 1945. These dates are considered remarkable because of two important facts: a lecture delivered by Batista de Lacerda on the positive features of mixing races during the World Congress of Races in London, and the end of the New State. To discuss the relationship between eugenics and education in Brazil we used as basis some Foucault principles, as the ones regarding biopolitics, governing, governmentality, regimes of truth and power-knowledge. The relationship between eugenics, education and government policy are considered as examples of biopolitical governmentality, when the Brazilian man, the "people" came to be seen as the body-type of the population. Issues related to the population' race assumed an important role in the educational political speech, because among the most important aspects of the eugenic movement in Brazil, was the formation of an eugenic conscience, which should be "inculcated" since childhood. An intellectual movement of great importance took the eugenic speech as a biopolitical strategy for the "race" improvement, and, was in the 1930s that this movement has achieved institutional success.
\end{abstract}

KEYWORDS: Education. Eugenic. Biopolitics. Brazilian history. 


\section{REFERÊNCIAS}

AZEVEDO, F. de. O problema da regeneração. Educação Physica, Rio de Janeiro, n.5, p.12-14, 1936.

AVELINO, N. Apresentação: Foucault e a anarqueologia dos saberes. In: FOUCAULT, M. O governo dos vivos: Curso no Collège de France, 1979-1980 (excertos). São Paulo: CCS-SP/Achiame, 2010. p.7-27.

BLACK, E. A guerra contra os fracos. São Paulo: A Girafa, 2003.

BRANCO, G. C. Ontologia do presente, racismo, lutas de resistência. In: PASSOS, I. C. F. (Org.). Poder, normalização e violência: incursões foucaultianas para a atualidade. Belo Horizonte: Autêntica, 2008. p.83-89.

BRASIL. Constituição (1934). Constituição da República dos Estados Unidos do Brasil (de 16 de julho de 1934). Rio de Janeiro, 1934. Nós, os representantes do povo brasileiro, pondo a nossa confiança em Deus, reunidos em Assembléia Nacional Constituinte para organizar um regime democrático, que assegure à Nação a unidade, a liberdade, a justiça e o bem-estar social e econômico, decretamos e promulgamos a seguinte. Disponível em:

<http://www.planalto.gov.br/ccivil_03/constituicao/constituicao34.htm>. Acesso em: 11 fev. 2014.

BRASIL. Constituição (1937). Constituição da República dos Estados Unidos do Brasil (de 10 de novembro de 1937). Rio de Janeiro, 1937. Disponível em:

<http://www.planalto.gov.br/ccivil_03/constituicao/constituicao37.htm>. Acesso em: 11 fev. 2014.

CARNEIRO, L. Educação e eugenia. In: CONGRESSO BRASILEIRO DE EUGENIA, 1., 1929, Rio de Janeiro. Atas e trabalhos... Rio de Janeiro: 1929. p.107-116.

CENTURIÃO, L. R. M. Racismo e nacional-socialismo. In: SILVA, M. L. da S. (Org.). Ciência, raça e racismo na modernidade. Santa Cruz do Sul: EDUNISC, 2009.

CHAVES, E. A dança nas escolas públicas de Minas Gerais: um estudo historiográfico de 1927 a 1937. In: CONGRESSO DE CIÊNCIAS HUMANAS, LETRAS E ARTES HUMANIDADES, UNIVERSIDADE E DEMOCRACIA, 2001, Ouro Preto. Anais eletrônicos... Ouro Preto: Universidade Federal de Ouro Preto, 2001. Disponível em: <http://www.ichs.ufop.br/conifes/anais/EDU/edu1706.htm>. Acesso em: 11 fev. 2014.

D’ALBUQUERQUE, T. O problema do robustecimento da juventude: a mulher allemã e os sportes. Educação Physica, Rio de Janeiro, n.13, p.18, 1937.

DANAILOF, K. Imagens da infância: a educação e o corpo em 1930 e 1940 no Brasil. Revista Brasileira de Ciências do Esporte, Campinas, v.26, n.3, p.25-40, mai. 2005.

DE LUCA, T. R. A revista do Brasil: um diagnóstico para a (N)ação. São Paulo: Ed. UNESP, 1999. 
DOMINGUES, O. Sciencias: mestiçamento e eugenia. São Paulo: Revista do Brasil, 1938.

EDITORIAL. Educação physica, Rio de Janeiro, n.11, 1937.

FOUCAULT, M. Vigiar e punir: história da violência nas prisões. Petrópolis: Vozes, 1991.

O governo dos vivos: Curso no Collège de France, 1979-1980 (excertos). São Paulo: CCS-SP/Achiame, 2010.

História da sexualidade: a vontade de saber. Rio de Janeiro: Graal, 2001.

GADELHA, S. Biopolítica, governamentalidade e educação: introdução e conexões, a partir de Michel Foucault. Belo Horizonte: Autêntica, 2009.

GALTON, F. Hereditary genius. London: Macmillan and CO, 1869.

Studies in eugenics: Restriction in Marriage. American Journal of Sociology, Chicago, v.11, n.1, p.11-25, jul. 1905. Disponível em: <http://galton.org/essays/19001911/galton-1906-eugenics.pdf>. Acesso em: 11 fev. 2014.

JARDIM, A. F. C. Michel Foucault e a educação: o investimento político do corpo. Unimontes Científica, Montes Claros, v.8, n.2, jul./dez. 2006.

KEHL, R. Eugenía e medicina social (problemas da vida). Rio de Janeiro: Livraria Francisco Alves, 1923.

LACERDA, J. B. Sobre os mestiços no Brasil. Primeiro Congresso Universal das Raças. Londres, jul. 1911. In: SCHWARCZ, L. M. Previsões são sempre traiçoeiras: João Baptista de Lacerda e seu Brasil branco. História, Ciências, Saúde: Manguinhos, Rio de Janeiro, v.18, n.1, p.225-242. jan./mar. 2011. Disponível em:

$<$ http://www.scielo.br/pdf/hcsm/v18n1/13.pdf>. Acesso em: 11 fev. 2014. p.234-242.

MARSHALL, J. Governamentalidade e Educação Liberal. In: SILVA, T. T. da (Org.). O sujeito da educação: estudos foucaultianos. Petrópolis: Vozes, 2010. p.21-34.

MENDES, M. I. B. de S.; NOBREGA, T. P. da. O Brazil-Medico e as contribuições do pensamento médico-higienista para as bases científicas da educação física brasileira. História, Ciências, Saúde: Manguinhos, Rio de Janeiro, v.15, n.1, p.209-219, 2008. Disponível em: <http://www.scielo.br/pdf/hcsm/v15n1/13.pdf>. Acesso em: 11 jun. 2012.

NEIVA, A.; PENNA B. Viagem científica: pelo norte da Bahia, sudoeste de Pernambuco, sul do Piauí e de Norte a Sul de Goiás. Brasília: Senado Federal, 1999. (Coleção Memória Brasileira, 17).

PELBART, P. P. Vida capital: ensaios de biopolítica. São Paulo: Iluminuras, 2011. 
PENNA, B. Prefácio. In: KEHL, R. Eugenía e medicina social (problemas da vida). Rio de Janeiro: Livraria Francisco Alves, 1923, p.III-IV.

PEREIRA, A. L. Darwin em Portugal (1865-1914): filosofia, história e engenharia social. Coimbra: Almedina, 2001.

ROCHA, S. A educação como ideal eugênico: o movimento eugenista e o discurso educacional no boletim de eugenia 1929-1933. Cadernos de pesquisa: pensamento educacional, Curitiba, v.6, n.13, p.162-177, 2011. Disponível em:

$<$ http://www.utp.br/Cadernos_de_Pesquisa/pdfs/cad_pesq13/11\%20_a_educacao_cp13. pdf>. Acesso em: 11 fev. 2014.

RODRIGUES, N. As raças humanas e a responsabilidade penal no Brazil. Rio de Janeiro: Ed. Guanabara, 1894.

SCHWARCZ, L. M. O espetáculo das raças. São Paulo: Companhia das Letras, 1993.

Previsões são sempre traiçoeiras: João Baptista de Lacerda e seu Brasil branco.

História, Ciências, Saúde: Manguinhos, Rio de Janeiro, v.18, n.1, p.225-242.

jan./mar. 2011. Disponível em: <http://www.scielo.br/pdf/hcsm/v18n1/13.pdf>. Acesso em: 11 fev. 2014.

SOUZA, V. S. de. Em nome da raça: a propaganda eugênica e as idéias de Renato Kehl nos anos 1910 e 1920. Revista de História Regional, Ponta Grossa, v.11, n.2, p.29-70, 2006. Disponível em: <www.revistas2.uepg.br/index.php/rhr/article/view/2230/1712>. Acesso em: 11 fev. 2014.

STEPHAN, N. L. A hora da eugenia: raça, gênero e nação na América Latina. Rio de Janeiro: FIOCRUZ, 2005.

STODDARD, T. L. The rising tide of color: against white world-supremacy. New York: Charles Scribner's Sons, 1922. Disponível em:

$<$ http://archive.org/stream/risingtideofcolo00stoduoft/risingtideofcolo00stoduoft_djvu.t xt>. Acesso em: 11 fev. 2014.

TESHAINER, M. C. R. Psicanálise e biopolítica: contribuição para a ética e a política em Michel Foucault. Porto Alegre: Zouk, 2006.

VEIGA-NETO, A. Foucault \& educação. Belo Horizonte: Autêntica, 2003.

. Na oficina de Foucault. In: GONDRA, J.; KOHAN, W. Foucault 80 anos.

Belo Horizonte: Autêntica, 2006. p.79-91.

VEIGA-NETO, A.; LOPES, M. C. Inclusão e governamentalidade. Educação e Sociedade, Campinas, v.28, n.100, p.947-963, out. 2007. 